\title{
The Evolving Role of Disulfiram in Radiobiology and the Treatment of Breast Cancer
}

This article was published in the following Dove Press journal:

OncoTargets and Therapy

\author{
Rui Wang \\ Jun Shen \\ Huanhuan Yan \\ Xitao Gao \\ Tianfu Dong \\ Peishun Wang \\ Jun Zhou
}

Department of Surgery, The First People's Hospital of Lianyungang,

Lianyungang, Jiangsu, China
Correspondence: Jun Zhou

Email dckaikai@sina.com

\begin{abstract}
Disulfiram (DSF), also known as "Antabuse", has been widely used in clinical practice to treat alcoholism. In the past decades, both in vivo and in vitro experiments showed that DSF has strong anti-cancer activity, there were some clinical studies indicated the administration of this drug was associated with favorable survival in breast cancer. It is also evident that DSF has a radioprotective effect on normal cells and could be utilized during the course of radiation therapy. Moreover, increasing evidences demonstrated the role of DSF in enhancing the radiosensitivity of tumor cells in number of alternative mechanisms. Recent studies have also elaborated the anticancer mechanism of DSF in tumor cells. This review summarizes the anticancer activity of DSF both in preclinical studies and clinical trials, focuses on the advances of this drug in radiobiology and the treatment of breast cancer, and reveals the promising of repurposing DSF as a novel radiosensitizer and radioprotector in further clinical trials.
\end{abstract}

Keywords: disulfiram, breast cancer, clinical studies, radiobiology, radiosensitivity

\section{Introduction}

Breast cancer remains the most common cancer and the second leading cause of cancer-related death among women in the world. ${ }^{1}$ There was strong evidence that getting older, the present of genetic mutations and women contribute to the carcinogenesis in human breast cancer. ${ }^{2}$ Primary treatment options for breast cancer including surgical resection, radiation therapy, chemotherapy, targeted therapy, immunotherapy and hormone therapy; and significant progress has been achieved. However, morbidity and mortality in breast tumor remains high, and thereby accelerating anticancer drug development is imminent. Generally, the development of new drugs has been estimated to be costly and a time-consuming process, and drug developers are opting drug-repurposing strategies to pre-existing drugs with secondary anticancer activity. ${ }^{3}$ Disulfiram (DSF), also called Antabuse, has emerged as a candidate for drug repurposing in anticancer therapy; the drug has been approved to treat alcoholism for more than sixty decades. ${ }^{4}$ Previous investigators have described the antitumor efficacy of DSF in breast cancer, and this drug has been reported to be well tolerated and with minimal severe side effects. ${ }^{4-6}$ Recently, the Danish-Czech-US research group retrospectively analyzed the Danish nationwide demographic and health registries, they found that there were more than 3000 patients diagnosed with cancer taking DSF between 2000 and 2013, and part of the patients were breast cancer; compared with patients who stopped taking DSF, it was reported to reduce the cancer morality by $34 \%$ in individuals who stayed on taking DSF. ${ }^{7}$ Further investigation revealed that 
DSF chelated copper $(\mathrm{Cu})$ and convert into bis (diethyldithiocarbamate)-Cu complex, this complex selectively targeted nuclear protein localization protein 4 homolog (NPL4) dependent segregase, and inducing cancer cell death. ${ }^{7}$ NPL4 is a component of the ubiquitin-proteasome system, this molecular is necessary for the export of misfolded proteins from the endoplasmic reticulum to the cytoplasm, and facilitates protein degradation. ${ }^{8}$ The misfolded protein degradation pathway played a crucial role in tumor cell radiation resistance. ${ }^{9}$ The cellular mechanisms of DSF in inducing cancer cell apoptosis have been well elaborated. Indeed, many studies demonstrated the process of DSF metabolized to diethyldithiocarbamate (DTC), DTC has antioxidant effects and can be served as a radioprotector in normal tissues; in addition, DSF was capable of enhancing radiosensitivity of breast cancer cells in number of alternative ways. ${ }^{10-13}$ This review elaborates the unique role of DSF in radiobiology and discussed its application in the treatment of breast cancer.

\section{Radioprotective Effects of DSF on Normal Cells}

One of the problems remains to be solved in radiobiological research is the protection of living cells from radiation induced damage, and various compounds have been investigated. ${ }^{14}$ The radioprotective effects of DSF have been extensively observed. Half a century ago, Stromme et al described the administration of DSF in mice, the drug metabolized to DTC and all of the animals were effectively protected against ionizing radiation. ${ }^{15}$ Since then, other findings have identified that radiation exposure could produce highly reactive free radicals, and DSF was a potent antioxidant that protected deoxyribose against damage in normal cells. ${ }^{10,16}$ In the L-929 mouse fibroblast cell lines, DSF was efficient in increasing tumor cells radiosensitivity while reducing radiation induced toxicity in normal tissues, and this effect was concentration dependent; further analyses revealed DSF's radiation modifier effect was modulated by its major metabolite-DTC. ${ }^{17}$ Although the molecular mechanism of DSF in normal tissue remains to be explored, these observations have led to enthusiasm that DSF could be used as a radioprotector (Figure 1). In addition, when exposed to gamma radiation, radiation induced damage in normal cells lead to the decreased quantity of the supercoiled form of plasmid pBR322 (deoxyribonucleic acid) DNA, especially the DNA strand broke; even irradiated at a dose of $300 \mathrm{~Gy}$, the plasmid DNA acquired complete protection in the presence of DSF; when the radiation dose increased to $600 \mathrm{~Gy}$, a nearly linear elevation of the membrane lipids peroxidation was detected, and the application of DSF

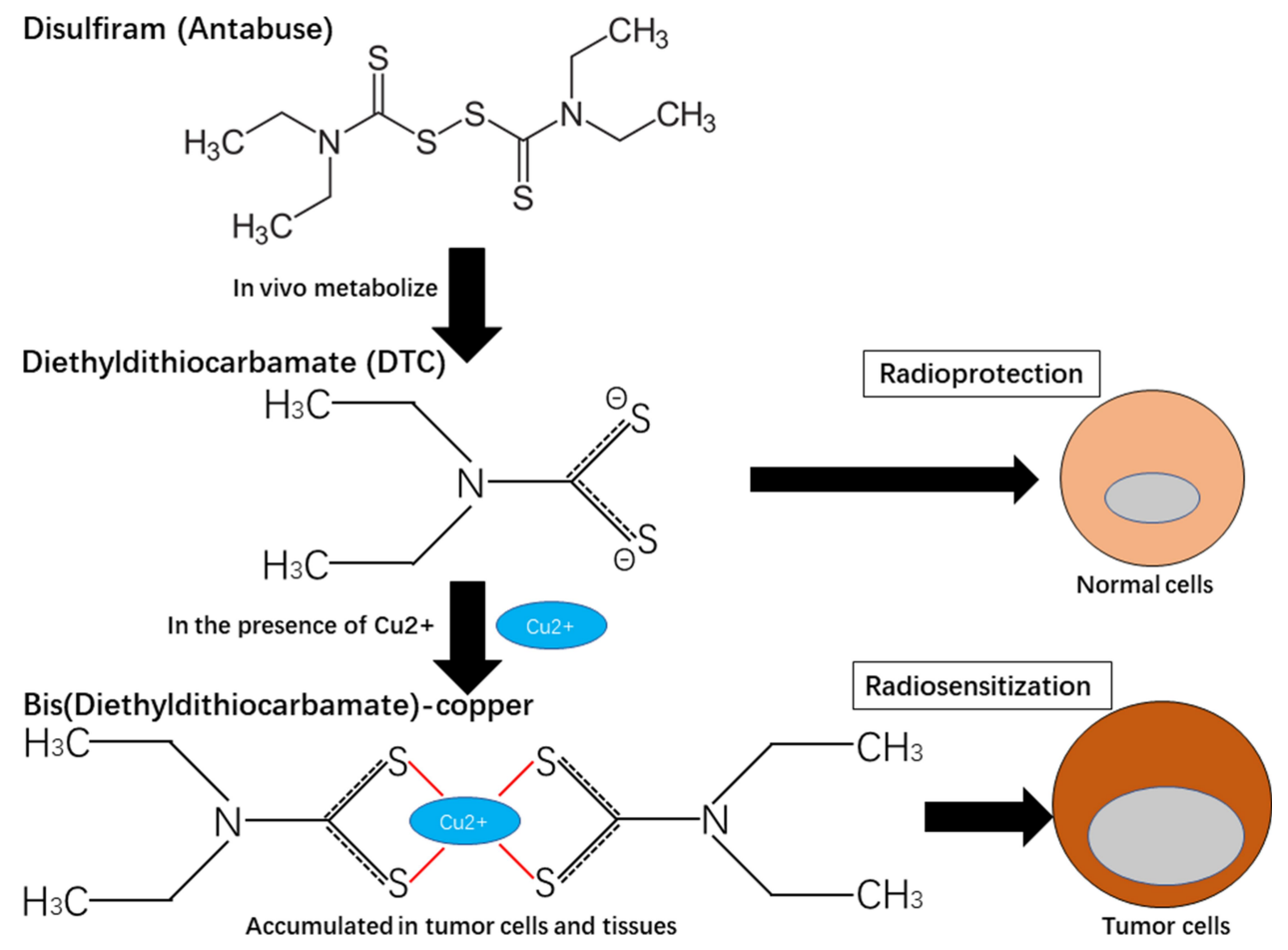

Figure I Metabolic differences of disulfiram (DSF) in cancer vs normal cells. 
resulted in decreased damage; in mice model, DSF was utilized prior to whole-body irradiation, both decreased cellular DNA damage and reduced membrane lipids peroxidation were observed in mice liver. ${ }^{10}$ Overall, it appeared that DSF protects DNA from radiation induced damage in normal tissues. It has been suggested that the radioprotective activity of DSF due to its ability to scavenge free radicals. ${ }^{10}$ Further studies are required to investigate the underlying molecular mechanisms. Nevertheless, these excellent results pave the way for further progress in the utilization of DSF as a promising radioprotector.

\section{DSF Sensitizes Breast Cancer Cells to Radiation Therapy}

For decades, much progress has been made in radiation therapy. However, local-regional recurrence and distant metastasis remains a problem and warrant improved treatment strategies in breast cancer. ${ }^{18}$ It is difficult to maximize the radiation dose administered to the tumor while minimizing unnecessary exposure to surrounding normal tissues. Radiosensitizers are compounds that make tumor cells more vulnerable to radiotherapy. ${ }^{9}$ The search for an effective and non-toxic radiosensitizer was a major concern in radiobiologists. DSF was a drug that capable of overcoming radiation resistance of cancer cells in the following ways: formed a complex with metal ions, elevated reactive oxygen species levels, inhibited the growth of cancer stem cells, and suppressed the activity of ubiquitin-proteasome system. ${ }^{10-13,19}$ Below we detailed how these mechanisms influence the radiosensitivity of breast cancer cells.

\section{DSF Binds to Metal lons}

The lack of metal ions decreased DSF's antitumor activity. It has been reported that DSF chelated bivalent metals and formed complexes with $\mathrm{Cu}$, and the $\mathrm{DSF} / \mathrm{Cu}$ complex was much more effective than DSF alone. ${ }^{20}$ In patients with cancer, an elevated $\mathrm{Cu}$ level was detected both in tumor tissues and the serum, further investigation revealed $\mathrm{Cu}$ involved in the biological process of tumorigenesis and metastasis. ${ }^{7,21}$ These features made DSF an ideal antitumor compound. DSF penetrated into tumor cells and binded intracellular $\mathrm{Cu}$ to form the apoptosis-inducing $\mathrm{Cu}$ complex. ${ }^{20}$ Previous study showed DSF/Cu complex inhibited breast cancer cell proliferation without significant toxicity. ${ }^{22}$ Likewise, there were synergistic interaction between $\mathrm{Cu}$-complexed DSF and radiation therapy. In radiation-resistant breast cancer cell lines, the efficacy of radiotherapy was enhanced by DSF in a $\mathrm{Cu}$-dependent manner; moreover, radiotherapy alone only triggered a low level of immunogenic cell death, DSF/Cu complex was able to increase radiotherapy-induced immunogenic cell death; further investigation revealed reactive oxygen species (ROS) generation and IRE1 $\alpha / \mathrm{XBP} 1$ signal pathway were partially responsible for improving radiotherapy-induced immunogenic cell death. ${ }^{23}$ These findings suggested DSF as a novel radiosensitizer in the existence of $\mathrm{Cu}$ for breast cancer.

\section{DSF Elevates ROS Levels}

Superoxide radicals play a pivotal role in radiationinduced cell death; however, cancer cells only contain a low level of superoxide dismutase. ${ }^{24,25}$ DSF and one of its metabolites DTC have been demonstrated to rise up the oxidative stress in tumor cells. ${ }^{26}$ Consequently, there were some studies focusing on the dynamic change of intracellular ROS levels when tumors were treated with radiotherapy and DSF. In Chinese hamster cells model, DTC, a $\mathrm{Cu}$ chelating agent, was administered during the course of radiation therapy, final results suggested that DTC inhibited the enzyme superoxide dismutase, promoting superoxide radical mediated toxicity of radiotherapy, and enhanced the radiosensitivity of tumor cells. ${ }^{27}$ In inflammatory breast cancer cellular model, the redox adaptive response of cancer cells evolved to evade ROS-mediated death, DSF/Cu complex has emerged as a redox modulator, inducing oxidative stress-mediated apoptosis and tumor cell radiosensitivity was improved; in addition, there was insignificant in vitro toxicity in normal cells. ${ }^{20}$ Taken together, the current findings revealed DSF was capable of regulating intracellular antioxidative defense systems in breast cancer and harmless to normal tissues.

\section{DSF Inhibits Cancer Stem Cells (CSCs) Formation}

Previous studies implied CSCs contribute to inherently resistant of breast tumor cells to radiation therapy. ${ }^{28,29}$ This suggested that targeting CSC may be an encouraging approach to killing tumor cells during radiation therapy. Aldehyde dehydrogenase (ALDH) belongs to the enzyme super family and catalyzes the oxidation aldehydes. ${ }^{30}$ Over the past few decades, there were evidences that ALDH1 as a marker of CSCs and tumor-initiating cells. ${ }^{31,32}$ As a result, ALDH could be served as a target in anticancer 
therapy. DSF was approved to treat alcoholism because its ability to inhibit the enzymatic activity of ALDH. ${ }^{33}$ Recent studies indicated that DSF combined with radiation therapy were efficient in suppressing CSCs. ${ }^{34,35}$ Radiationinduced CSCs were inhibited by the nuclear factor kappa $\mathrm{B}(\mathrm{NF}-\mathrm{\kappa B})$ stemness gene pathway with $\mathrm{DSF} / \mathrm{Cu}$ complexes in vitro; in a breast cancer xenograft mouse model, DSF induced cell apoptosis, prevented tumor growth and reduced the incidences of cell metastasis when combined with radiation therapy. ${ }^{35}$ These evidence implied a role of NF- $\kappa B$ signaling in the biology of CSC and suggested DSF may become a new radiation sensitizer in breast cancer.

\section{DSF/Cu Suppresses}

\section{Ubiquitin-Proteasome System (UPS)}

The UPS is critical to cellular proteins catabolism and involves in signal transduction, cell cycle progression, apoptosis, chromosome maintenance as well as other biological processes. ${ }^{36}$ To date, there were several studies indicated UPS participated in radiation-induced cancer cell death. ${ }^{37,38}$ In human radiation-resistant breast cancer cell lines, $\mathrm{DSF} / \mathrm{Cu}$ acted as an effective proteasome blocker in suppressing the NF-kB pathway and enhancing the efficacy of radiotherapy. ${ }^{35} \mathrm{DSF} / \mathrm{Cu}$ complexes have been shown to affect proteasome function and served as a radiosensitizer both in vitro and in vivo, and the evaluation of DSF as an adjuvant agent in patients receiving radiation therapy was necessary.

\section{Future Challenges}

Currently, the evidence keeps accumulating that DSF involved in overcoming radiation resistance in cancer cells; and laboratory studies have also revealed the antiangiogenesis and epigenetic modifications of this drug. $^{39,40}$ However, relevant studies in breast cancer were extremely rare, some of the studies have not been well investigated, and the underlying mechanism of DSF's radiosensitization effect remains to be elucidated. The lack of large-scale, prospective, observational studies limited the application of DSF as a radiosensitizer and a radioprotector in daily clinical practice. Even though our knowledge of DSF and its molecular mechanisms in regulating cells response to irradiation has continued to grow, and this provided DSF as a promising drug that may reduce the adverse effect of radiation therapy and decrease the local failure rates of breast cancer.

\section{Conclusion}

DSF was an old, inexpensive and tolerable drug to treat alcoholism, and has already passed safety testing. The anticancer activity of this drug was $\mathrm{Cu}$-dependent and has been well elaborated in breast cancer. While the radioprotective effects of DSF in normal cells and radiosensitizing activity of this compound in breast tumor cells still needed full investigation, utility of DSF as a potential radiosensitizer was well recognized (Figure 1). Finding a new use for an approved drug was appealing. Currently, there were two clinical trials focusing on the application of DSF in metastatic breast cancer (NCT04265274. NCT03323346), these results will convincingly contribute to clinical evaluation of DSF as a pre-existing drug that may increase the efficacy of radiation therapy.

\section{Abbreviations}

$\mathrm{ALDH}$, aldehyde dehydrogenase; $\mathrm{Cu}$, copper; $\mathrm{CSC}$, cancer stem cells; DSF, disulfiram; DTC, diethyldithiocarbamate; DNA, deoxyribonucleic acid; NF- $\kappa B$, nuclear factor kappa B; NPL4, nuclear protein localization protein 4 homolog; ROS, reactive oxygen species; UPS, ubiquitin-proteasome system.

\section{Funding}

There is no funding to report.

\section{Disclosure}

The authors have no potential conflicts of interest relevant to the content of this manuscript.

\section{References}

1. Siegel RL, Miller KD, Jemal A. Cancer statistics, 2020. CA Cancer J Clin. 2020;70:7-30. doi:10.3322/caac.21590

2. Sun YS, Zhao Z, Yang ZN, et al. Risk factors and preventions of breast cancer. Int J Biol Sci. 2017;13:1387-1397. doi:10.7150/ijbs.21635

3. Collins FS. Mining for therapeutic gold. Nat Rev Drug Discov. 2011;10:397. doi:10.1038/nrd3461

4. Cvek B. Nonprofit drugs as the salvation of the world's healthcare systems: the case of Antabuse (disulfiram). Drug Discov Today. 2012;17:409-412. doi:10.1016/j.drudis.2011.12.010

5. Dufour P, Lang JM, Giron C, et al. Sodium dithiocarb as adjuvant immunotherapy for high risk breast cancer: a randomized study. Biotherapy. 1993;6:9-12. doi:10.1007/BF01877380

6. Nechushtan H, Hamamreh Y, Nidal S, et al. A phase IIb trial assessing the addition of disulfiram to chemotherapy for the treatment of metastatic non-small cell lung cancer. Oncologist. 2015;20:366-367. doi:10.1634/theoncologist.2014-0424

7. Skrott Z, Mistrik M, Andersen KK, et al. Alcohol-abuse drug disulfiram targets cancer via p97 segregase adaptor NPL4. Nature. 2017;552:194-199. doi:10.1038/nature25016 
8. Sato Y, Tsuchiya H, Yamagata A, et al. Structural insights into ubiquitin recognition and Ufd1 interaction of Np14. Nat Commun. 2019;10:5708. doi:10.1038/s41467-019-13697-y

9. Luo H, Song H, Mao R, et al. Targeting valosin-containing protein enhances the efficacy of radiation therapy in esophageal squamous cell carcinoma. Cancer Sci. 2019;110:3464-3475. doi:10.1111/ cas. 14184

10. Gandhi NM, Gopalaswamy UV, Nair C. Radiation protection by disulfiram: protection of membrane and DNA in vitro and in vivo against gamma-radiation. $J$ Radiat Res. 2003;44:255-259. doi: $10.1269 /$ jrr.44.255

11. Cong J, Wang Y, Zhang X, et al. A novel chemoradiation targeting stem and nonstem pancreatic cancer cells by repurposing disulfiram. Cancer Lett. 2017;409:9-19. doi:10.1016/j.canlet.2017.08.028

12. Lee YE, Choi SA, Kwack PA, et al. Repositioning disulfiram as a radiosensitizer against atypical teratoid/rhabdoid tumor. Neuro Oncol. 2017;19:1079-1087. doi:10.1093/neuonc/now300

13. Tesson M, Anselmi G, Bell C, Mairs R. Cell cycle specific radiosensitisation by the disulfiram and copper complex. Oncotarget. 2017;8:65900-65916. doi:10.18632/oncotarget.19539

14. Szejk M, Kolodziejczyk-Czepas J, Zbikowska HM. Radioprotectors in radiotherapy - advances in the potential application of phytochemicals. Postepy Hig Med Dosw. 2016;70:722-734. doi:10.5604/17322693.1208039

15. Stromme JH, Eldjarn L. Distribution and chemical forms of diethyldithiocarbamate and tetraethylthiuram disulphide (disulfiram) in mice in relation to radioprotection. Biochem Pharmacol. 1966;15:287-297. doi:10.1016/0006-2952(66)90300-5

16. Ito Y, Cai H, Koizumi Y, et al. Effects of lipid composition on the transcorneal penetration of liposomes containing disulfiram, a potential anti-cataract agent, in the rabbit. Biol Pharm Bull. 2000;23:327-333. doi:10.1248/bpb.23.327

17. Taylor RD, Maners AW, Salari H, Baker M, Walker EM Jr. Disulfiram as a radiation modifier. Ann Clin Lab Sci. 1986;16:443-449.

18. Fung F, Cornacchi SD, Vanniyasingam T, et al. Predictors of 5-year local, regional, and distant recurrent events in a population-based cohort of breast cancer patients. Am J Surg. 2017;213:418-425. doi:10.1016/j.amjsurg.2016.03.016

19. Rae C, Tesson M, Babich JW, Boyd M, Sorensen A, Mairs RJ. The role of copper in disulfiram-induced toxicity and radiosensitization of cancer cells. J Nucl Med. 2013;54:953-960. doi:10.2967/jnumed. 112.113324

20. Allensworth JL, Evans MK, Bertucci F, et al. Disulfiram (DSF) acts as a copper ionophore to induce copper-dependent oxidative stress and mediate anti-tumor efficacy in inflammatory breast cancer. $\mathrm{Mol}$ Oncol. 2015;9:1155-1168. doi:10.1016/j.molonc.2015.02.007

21. Schmitt SM, Frezza M, Dou QP. New applications of old metal-binding drugs in the treatment of human cancer. Front Biosci. 2012;4:375-391. doi:10.2741/s274

22. Chen D, Cui QC, Yang H, Dou QP. Disulfiram, a clinically used anti-alcoholism drug and copper-binding agent, induces apoptotic cell death in breast cancer cultures and xenografts via inhibition of the proteasome activity. Cancer Res. 2006;66:10425-10433. doi:10.1158/0008-5472.can-06-2126

23. Sun T, Yang W, Toprani SM, et al. Induction of immunogenic cell death in radiation-resistant breast cancer stem cells by repurposing anti-alcoholism drug disulfiram. Cell Commun Signal. 2020;18:36. doi:10.1186/s12964-019-0507-3
24. Powell S, McMillan TJ. DNA damage and repair following treatment with ionizing radiation. Radiother Oncol. 1990;19:95-108. doi:10.1016/0167-8140(90)90123-E

25. Diehn M, Cho RW, Lobo NA, et al. Association of reactive oxygen species levels and radioresistance in cancer stem cells. Nature. 2009;458:780-783. doi:10.1038/nature07733

26. Bruning A, Kast RE. Oxidizing to death: disulfiram for cancer cell killing. Cell Cycle. 2014;13:1513-1514. doi:10.4161/cc.28959

27. Lin PS, Kwock L, Butterfield CE. Diethyldithiocarbamate enhancement of radiation and hyperthermic effects on Chinese hamster cells in vitro. Radiat Res. 1979;77:501-511. doi:10.2307/3575161

28. Yadav P, Shankar BS. Radio resistance in breast cancer cells is mediated through TGF-beta signalling, hybrid epithelial-mesenchymal phenotype and cancer stem cells. Biomed Pharmacother. 2019;111:119-130. doi:10.1016/j.biopha.2018.12.055

29. Arnold KM, Opdenaker LM, Flynn NJ, Appeah DK, Sims-Mourtada J. Radiation induces an inflammatory response that results in STAT3-dependent changes in cellular plasticity and radioresistance of breast cancer stem-like cells. Int J Radiat Biol. 2020;96:434-447. doi:10.1080/09553002.2020.1705423

30. Marchitti SA, Brocker C, Stagos D, Vasiliou V. Non-P450 aldehyde oxidizing enzymes: the aldehyde dehydrogenase superfamily. Expert Opin Drug Metab Toxicol. 2008;4:697-720. doi:10.1517/ 17425255.4.6.697

31. Huang EH, Hynes MJ, Zhang T, et al. Aldehyde dehydrogenase 1 is a marker for normal and malignant human colonic stem cells (SC) and tracks SC overpopulation during colon tumorigenesis. Cancer Res. 2009;69:3382-3389. doi:10.1158/0008-5472.can-08-4418

32. Choi SA, Lee JY, Phi JH, et al. Identification of brain tumour initiating cells using the stem cell marker aldehyde dehydrogenase. Eur J Cancer. 2014;50:137-149. doi:10.1016/j.ejca.2013.09.004

33. Suh JJ, Pettinati HM, Kampman KM, O'Brien CP. The status of disulfiram: a half of a century later. J Clin Psychopharmacol. 2006;26:290-302. doi:10.1097/01.jcp.0000222512.25649.08

34. Triscott J, Rose Pambid M, Dunn SE. Concise review: bullseye: targeting cancer stem cells to improve the treatment of gliomas by repurposing disulfiram. Stem Cells. 2015;33:1042-1046. doi:10.1002/ stem. 1956

35. Wang Y, Li W, Patel SS, et al. Blocking the formation of radiation-induced breast cancer stem cells. Oncotarget. 2014;5:3743-3755. doi:10.18632/oncotarget.1992

36. Nandi D, Tahiliani P, Kumar A, Chandu D. The ubiquitin-proteasome system. J Biosci. 2006;31:137-155.

37. McBride WH, Iwamoto KS, Syljuasen R, Pervan M, Pajonk F. The role of the ubiquitin/proteasome system in cellular responses to radiation. Oncogene. 2003;22:5755-5773. doi:10.1038/sj.onc.120 6676

38. Ahmed KM, Li JJ. NF-kappa B-mediated adaptive resistance to ionizing radiation. Free Radic Biol Med. 2008;44:1-13. doi:10.1016/j.freeradbiomed.2007.09.022

39. Paranjpe A, Zhang R, Ali-Osman F, Bobustuc GC, Srivenugopal KS. Disulfiram is a direct and potent inhibitor of human O6-methylguanineDNA methyltransferase (MGMT) in brain tumor cells and mouse brain and markedly increases the alkylating DNA damage. Carcinogenesis. 2014;35:692-702. doi:10.1093/carcin/bgt366

40. Li Y, Fu SY, Wang LH, et al. Copper improves the anti-angiogenic activity of disulfiram through the EGFR/Src/VEGF pathway in gliomas. Cancer Lett. 2015;369:86-96. doi:10.1016/j.canlet.2015. 07.029 


\section{Publish your work in this journal}

OncoTargets and Therapy is an international, peer-reviewed, open access journal focusing on the pathological basis of all cancers, potential targets for therapy and treatment protocols employed to improve the management of cancer patients. The journal also focuses on the impact of management programs and new therapeutic agents and protocols on patient perspectives such as quality of life, adherence and satisfaction. The manuscript management system is completely online and includes a very quick and fair peer-review system, which is all easy to use. Visit http://www.dovepress.com/ testimonials.php to read real quotes from published authors.

Submit your manuscript here: https://www.dovepress.com/oncotargets-and-therapy-journal 